\title{
Prescrições de antibacterianos em uma drogaria do município de Tanabi, São Paulo, Brasil
}

\author{
Antibacterial prescriptions in a drugstore at Tanabi, São Paulo, Brazil
}

Recebido em: 09/06/2017

Aceito em: $22 / 07 / 2017$
Tiago Aparecido MASCHIO DE LIMA' ${ }^{1}$; Tamiris Campos da SILVA ${ }^{2}$; Luis Lênin Vicente PEREIRA' ${ }^{2}$; Moacir Fernandes de GODOY ${ }^{1}$ ${ }^{1}$ Faculdade de Medicina de São José do Rio Preto, Famerp. Avenida Brigadeiro Faria Lima, 5416, Vila São Pedro, CEP 15090-000. São José do Rio Preto, SP, Brasil.

${ }^{2}$ União das Faculdades dos Grandes Lagos, Unilago. Rua Doutor Nielsem, 960, Jardim Aeroporto, CEP 15030-070. São José do Rio Preto, SP, Brasil.

E-mail: tiagomaschio.farmacip@gmail.com

\begin{abstract}
Antimicrobial drugs are substances able to prevent the proliferation or death of infectious agents, combating and preventing the dissemination of an infection. The abusive or inappropriate use of these drugs leads to the development of strains of multi-resistant microrganisms. The aim of this study was to describe the antimicrobial drug consumption in a drugstore at Tanabi, São Paulo, Brazil. This is a retrospective, descriptive, exploratory study with a quantitative approach. There were analyzed 128 prescriptions containing antimicrobial drugs dispensed in $2016.64 \%$ of the prescriptions were destined to the female gender. The average age was $46 \pm 25$ years. The most prescribed antimicrobials were cephalexin (23\%), amoxicillin associated with clavulanate (22\%), ciprofloxacin (17\%) and azithromycin $(15 \%)$. Consequently, the most commonly used pharmacological groups were beta-lactams $(55 \%)$, fluoroquinolones $(30 \%)$ and macrolides (15\%), respectively. The most frequent prescribers were general phisicians $(42 \%)$, dentist $(12 \%)$, cardiologist (9\%) and urologist (7\%). Most of the prescriptions came from the private health system (54\%). The prescribers used the trade name in 55\% of the prescribed antimicrobials, of which $33 \%$ were destined to the public health system. This research contributes to evaluation of the use of antimicrobial drugs in population. The effective action of the Pharmacist in the control the use of antibacterials in accordance with current legislation is important to provide the population with adequate guidelines on the rational use of these agents.
\end{abstract}

Keywords: Drug utilization; Anti-bacterial agents; Prescription drugs; Pharmacy.

\section{RESUMO}

Os antimicrobianos são substâncias que previnem a proliferação ou provocam a morte de fungos ou bactérias, combatendo e prevenindo o avanço de uma infecção. O uso abusivo ou inadequado desses fármacos acarreta o desenvolvimento de cepas de multirresistentes $\mathrm{O}$ objetivo desse estudo foi descrever o perfil de consumo de antibióticos em uma drogaria do município de Tanabi, São Paulo, Brasil. Trata-se de um estudo retrospectivo, descritivo, exploratório com abordagem quantitativa. Foram analisadas 128 cópias das prescrições de antibióticos recebidas durante o ano de 2016. $64 \%$ das prescrições foram destinadas ao sexo feminino. A média de idade foi $46 \pm 25$ anos. Os antibióticos mais prescritos foram cefalexina (23\%), amoxicilina associada ao clavulanato (22\%), ciprofloxacino (17\%) e azitromicina $(15 \%)$. Consequentemente, os grupos farmacológicos mais utilizados foram beta-lactâmicos (55\%), fluoroquinolonas $(30 \%)$ e macrolídeos $(15 \%)$. Os prescritores mais frequentes foram médicos generalistas $(42 \%$, ) dentistas $(12 \%)$, cardiologistas (9\%) e urologistas (7\%). A maior parte das prescrições foi advinda do sistema privado de saúde (54\%). Os prescritores utilizaram o nome comercial em 55\% dos antibacterianos prescritos, dos quais $33 \%$ foram oriundos do Sistema Único de Saúde. Esta pesquisa contribui na avaliação do uso de medicamentos antibióticos na população. A atuação efetiva do farmacêutico no controle do uso de antibióticos de acordo com a legislação vigente é importante para prover a população com orientações adequadas sobre o uso racional desses agentes.

Palavras-chave: Uso de medicamentos; Antibacterianos; Medicamentos sob prescrição; Farmácia.. 


\section{INTRODUÇÃO}

Os antibióticos são substâncias que previnem a proliferação ou provocam a morte de bactérias e fungos, combatendo e prevenindo o avanço de uma infecção (1). Esses fármacos podem atuar como bactericidas, destruindo a parede celular e causando a morte, ou bacteriostáticos, inibindo seu crescimento e evitando a multiplicação (1).

Nas infecções comunitárias, os antibacterianos comumente utilizados são os macrolídeos (inibidores da síntese proteica), os beta-lactâmicos (inibidores da síntese da parede celular), as fluoroquinolonas e sulfonamidas (que atuam sobre o material genético bacteriano). Todos devem ser utilizados de forma racional, com correta indicação, dose, posologia e duração do tratamento (2).

$\mathrm{O}$ uso abusivo, indiscriminado ou inadequado de medicamentos antibacterianos acarreta desenvolvimento de cepas de bactérias multirresistentes que não respondem ao efeito terapêutico desses agentes, podendo dificultar o tratamento de futuras infecções, bem como o agravamento dos quadros das doenças (3). A resistência bacteriana ocorre quando os patógenos se multiplicam na presença de concentrações antimicrobianas terapêuticas necessárias para o tratamento de uma infecção (4).

Em decorrência disso, no ano de 2010, a Agência Nacional de Vigilância Sanitária (Anvisa), publicou a Resolução $n^{\circ} 44$ (5), que posteriormente foi atualizada pela Resolução n 20 em 2011, estabelecendo maior controle no acesso aos medicamentos antimicrobianos, seja no setor público ou privado (6).

A resolução vigente determina que a prescrição de antimicrobianos seja efetuada apenas por profissionais legalmente habilitados, sendo expedida em duas vias brancas, legíveis, sem rasuras e contendo todos os dados obrigatórios de identificação do paciente, do emissor e do medicamento, e aviada dentro do prazo máximo de dez dias a contar da data de emissão. Durante a dispensação, o estabelecimento deve reter a segunda via da prescrição e devolver primeira ao paciente. Em ambas as vias devem ser anotados a data da dispensação, a quantidade aviada, o número do lote do medicamento e a assinatura do farmacêutico responsável. Ademais, todas as entradas e saídas devem ser registradas no Sistema Nacional de Gerenciamento de Produtos Controlados (SNGPC) (6).

O farmacêutico é um profissional diretamente envolvido com a política do uso racional de medicamentos e exerce um papel fundamental na prevenção do uso inadequado dos medicamentos antibacterianos, atuando na avaliação de prescrições de acordo com a legislação vigente e evidências científicas, identificando problemas relacionados ao uso de antibacterianos, como reações adversas e interações medicamentosas, além de fornecer orientações à população sobre o uso e armazenamento apropriado, e avaliar a adesão ao tratamento prescrito. Ademais, é necessária a integração entre prescritores e dispensadores permitindo uma combinação de conhecimentos especializados e complementares $(7,8)$.

Alguns fatores contribuem para o uso irracional de antibacterianos, como a automedicação, a deficiência no acesso aos serviços de saúde, as dificuldades de diagnóstico nas doenças infecciosas, e a falta de fiscalização na dispensação desses fármacos, aumentando assim, o risco de resistência bacteriana $(3,4)$.

Dessa forma, estudos são necessários para verificar a adequação dos receituários emitidos em relação aos fatores importantes para o uso racional de medicamentos antibacterianos. Assim, o objetivo desse trabalho foi descrever o consumo de medicamentos antibacterianos em uma drogaria do município de Tanabi, São Paulo, Brasil.

\section{MÉTODOS}

Trata-se de um estudo retrospectivo, descritivo, exploratório com abordagem quantitativa. Foram analisadas as cópias de todas as prescrições de antibióticos recebidas durante os meses de janeiro a dezembro de 2016, em uma drogaria localizada no município de Tanabi, São Paulo, Brasil, a partir da autorização prévia por escrito do responsável pelo estabelecimento. O município deste estudo possui cerca de 20 farmácias e drogarias privadas e a estimativa da população para o ano de 2016 foi de 25.597 habitantes (9).

Foram incluídas as prescrições que continham pelo menos um antibacteriano, de pacientes de ambos os sexos e de todas as faixas etárias. Foram excluídas as prescrições de antibacterianos de uso tópico, antivirais e antifúngicos.

Foram coletadas as seguintes variáveis em cada prescrição: dados demográficos (sexo e idade), profissional prescritor envolvido, origem do sistema de saúde da prescrição (público ou privado), antibacterianos prescritos, prescrição pelo nome comercial ou genérico. Posteriormente, os antibacterianos foram classificados de acordo com o grupo farmacológico (3).

As variáveis foram coletadas por uma pesquisadora, que possui experiência como atendente em drogaria, e foi realizada uma segunda checagem coordenador do 
projeto. O contato com o prescritor para adequação das prescrições, quando necessário, foi realizado de acordo com a rotina do estabelecimento.

Os dados das prescrições foram transferidos para um banco de dados, utilizando a planilha do software Microsoft Excel ${ }^{\circledR}, 2010$. Foi realizada uma análise esta-

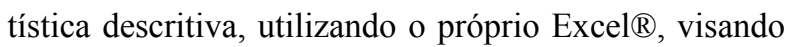
caracterizar as variáveis encontradas nas prescrições. As variáveis categóricas foram apresentadas com números e proporções (\%). Variáveis contínuas com distribuição normal foram apresentadas como média \pm desvio padrão. $\mathrm{O}$ teste $\mathrm{t}$ de Student foi empregado para testar a diferença entre as médias, sendo considerado $p<0,05$ estatisticamente significante. Bioestat versão 5.0 foi utilizado nas análises.

O estudo foi iniciado após aprovação pelo Comitê de Ética em Pesquisa da União da Faculdade dos Grandes Lagos (Unilago), sob o parecer número: 2.007.506.

\section{RESULTADOS E DISCUSSÃO}

Foram analisadas 128 prescrições de antibacterianos recebidas na drogaria do estudo durante o ano de 2016. Os antibacterianos mais prescritos foram cefalexina $(\mathrm{N}=30 ; 23 \%)$, amoxicilina associada ao clavulanato $(\mathrm{N}=28 ; 22 \%)$, ciprofloxacino $(\mathrm{N}=22 ; 17 \%)$, e azitromicina $(\mathrm{N}=19 ; 15 \%)$. Consequentemente, os grupos farmacológicos mais utilizados foram beta-lactâmicos $(\mathrm{N}=71$; $55 \%)$, fluoroquinolonas $(\mathrm{N}=38 ; 30 \%)$ e macrolídeos $(\mathrm{N}=19 ; 15 \%)$. Os dados encontram-se pormenorizados na Tabela 1.

Tabela 1. Descrição e classificação dos 128 antimicrobianos prescritos em uma drogaria no município de Tanabi, São Paulo, Brasil (2016).

\begin{tabular}{|c|c|c|}
\hline Variável & $\mathbf{n}$ & $\%$ \\
\hline \multicolumn{3}{|l|}{ Antimicrobiano } \\
\hline cefalexina & 30 & 23 \\
\hline amoxicilina+clavulanato & 28 & 22 \\
\hline ciprofloxacino & 22 & 17 \\
\hline azitromicina & 19 & 15 \\
\hline levofloxacino & 14 & 11 \\
\hline amoxicilina & 13 & 10 \\
\hline norfloxacino & 2 & 2 \\
\hline \multicolumn{3}{|l|}{ Grupo farmacológico } \\
\hline beta-lactâmico & 71 & 55 \\
\hline fluoroquinolonas & 38 & 30 \\
\hline macrolídeos & 19 & 15 \\
\hline
\end{tabular}

Quanto aos dados demográficos deste estudo, 64\% $(\mathrm{N}=82)$ das prescrições foram destinadas ao sexo feminino e $36 \%(\mathrm{~N}=46)$ ao masculino. A média de idade foi de $46 \pm 25$ anos, mediana 50, mínima três e idade máxima de 94 anos. Houve associação estatisticamente significante entre a média de antibacterianos consumidos e o sexo feminino $(p=0,010)$. Não houve associação significante entre o consumo de antibacterianos e a idade.

Os prescritores mais frequentes foram médicos generalistas $(\mathrm{N}=54 ; 42 \%)$, seguida por dentistas $(\mathrm{N}=15$; $12 \%)$, cardiologistas $(\mathrm{N}=12 ; 9 \%)$ e urologistas $(\mathrm{N}=10$; $7 \%$ ). A maior parte das prescrições foi advinda do sistema privado de saúde (N=69;54\%), e (N=59;46\%) do Sistema Único de Saúde (SUS).

Tabela 2. Características das 128 prescrições de antimicrobianos analisadas no município de Tanabi, São Paulo, Brasil, 2016.

\begin{tabular}{|lll|}
\hline \multicolumn{1}{|c}{ Variável } & $\mathbf{n}$ & \% \\
\hline Prescritor & & \\
\hline Médico generalista & 54 & 42 \\
\hline Dentista & 15 & 12 \\
\hline Cardiologista & 12 & 9 \\
\hline Urologista & 10 & 7 \\
\hline Ginecologista & 6 & 5 \\
\hline Otorrinolaringologista & 5 & 4 \\
\hline Ortopedista & 5 & 4 \\
\hline Cirurgião plástico & 4 & 3 \\
\hline Pediatra & 4 & 3 \\
\hline Gastroenterologista & 3 & 2 \\
\hline Obstetra & 3 & 2 \\
\hline Dermatologista & 2 & 2 \\
\hline Pneumologista & 2 & 2 \\
\hline Cirurgião vascular & 2 & 2 \\
\hline Proctologista & 1 & 1 \\
\hline Sistema de origem & 59 & 56 \\
\hline Público & 59 & 55 \\
\hline Privado & 70 & \\
\hline Nomenclatura & & \\
\hline Denomercial & 59 & \\
\hline
\end{tabular}

Os prescritores utilizaram o nome comercial em $55 \%(\mathrm{~N}=70)$ dos antibacterianos prescritos, e a Denominação Comum Brasileira (DCB) em 45\% (N=58) das prescrições. Dentre os antibacterianos prescritos pelo 
nome comercial, $33 \%(\mathrm{~N}=19)$ foram oriundos do SUS. Os dados das prescrições encontram-se descritos na Tabela 2

A Figura 1 mostra o consumo de antibacterianos no decorrer dos meses do ano de 2016. Foi observado um aumento no consumo de antibacterianos nos meses de inverno.

Nesse estudo foi observada a prescrição frequente de beta-lactâmicos, fluoroquinolonas, em uma amostra com predominância do sexo feminino e com idade variada. Também envolveu diferentes prescritores, e a DCB não constava em todas as prescrições oriundas do SUS. Quanto à sazonalidade foi observado um consumo um pouco maior nos meses de inverno.

Por se tratar de um estudo descritivo a partir da análise de prescrições e não utilização de entrevistas com os participantes, não foi possível analisar as indicações dos antibacterianos prescritos e avaliar o conhecimento da amostra em relação ao tratamento antibacteriano e a resistência bacteriana. Estudos observacionais para investigar estas limitações podem ser sugeridos.

Nesse estudo, a maior parte das prescrições foi destinada ao sexo feminino. Outros estudos realizados nos municípios em diferentes Estados brasileiros, tais como Jataí, GO, João Pessoa, PB, Cruz Alta, RS, e Colider, MS, corroboram com esse dado (10-13). O maior consumo de antibacterianos entre as mulheres é justificado pela maior procura aos serviços de saúde, além das condições anatômicas e da microbiota feminina favorecerem a ocorrência de infecções do trato geniturinário (14).

Em relação aos grupos farmacológicos, os mais utilizados nesse estudo foram beta-lactâmicos, fluorquinolonas e macrolídeos. Outros estudos realizados em farmácias e drogarias corroboram com estes dados, como o estudo realizado em três drogarias de Goiás no ano de 2015, que mostrou uma maior frequência de beta-lactâmicos e quinolonas dentre os 706 antibacterianos prescritos (15); os estudos realizados em João Pessoa, PB, 2012, e Colider, MT, 2015, onde os pesquisadores também relataram beta-lactâmicos como os mais prescritos $(11,13)$. Por outro lado, no estudo realizado em Manaus, AM com três drogarias no ano de 2011, avaliando 759 prescrições, os mais prescritos foram quinolonas, penicilinas e aminoglicosídeos (16).

Os antibacterianos mais prescritos nesse estudo, respectivamente, foram cefalexina, amoxicilina associada ao clavulanato, ciprofloxacino e azitromicina. Em Jataí ,GO, os antibacterianos mais utilizados foram amoxicilina e cefalexina (10). Ainda em Goiás, no município de Uruana, houve maior consumo de amoxicilina, seguido pela azitromicina e ciprofloxacino (15).

Cefalexina e amoxicilina, o primeiro e o segundo mais prescritos, são beta-latâmicos inibidores da parede celular bacteriana, sendo o primeiro pertencente ao grupo das cefalosporinas semissintéticas de primeira geração e o segundo ao grupo das penicilinas semissintéticas $(17,18)$. A amoxicilina, geralmente, é prescrita em associação a um inibidor da beta-lactamase, como

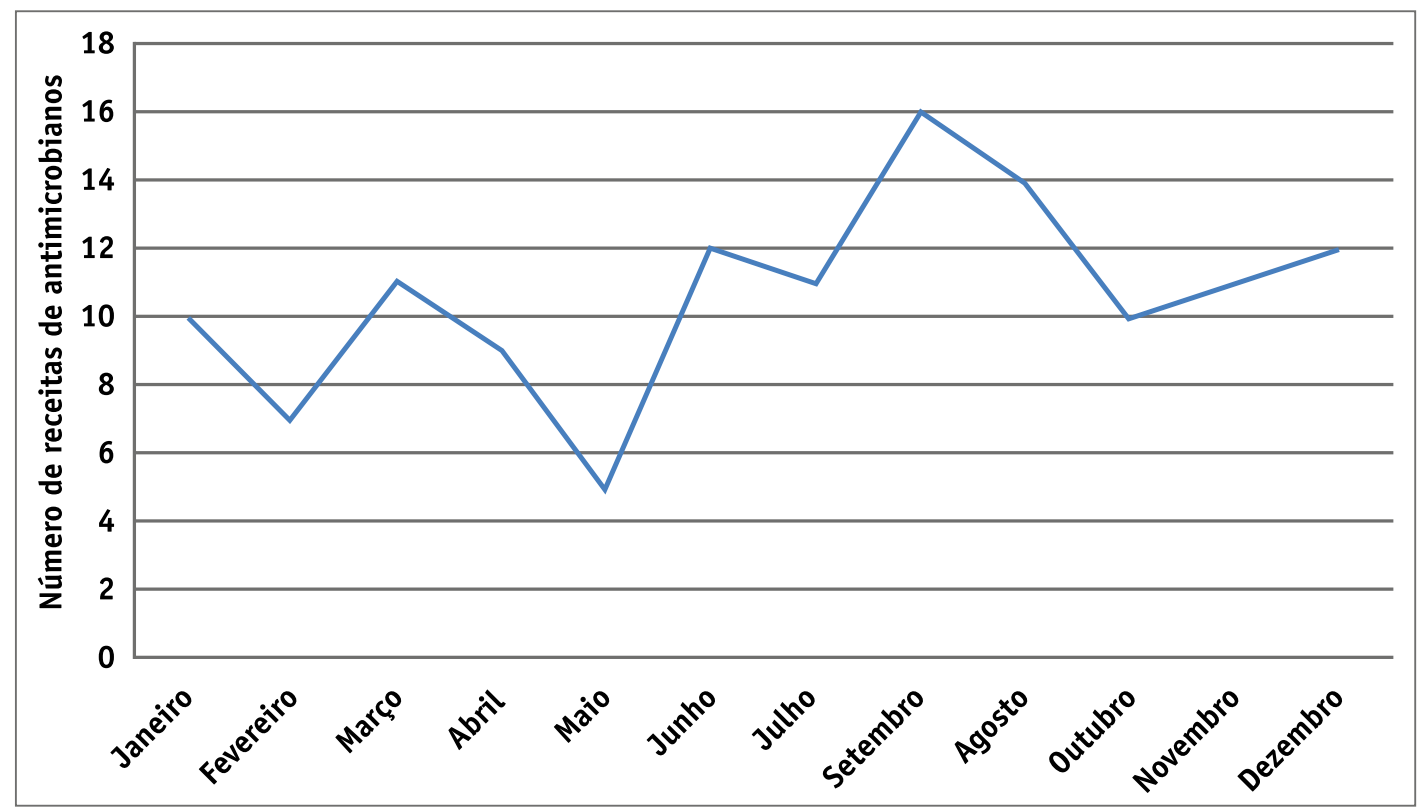

Figura 1. Consumo de antimicrobianos em drogaria do município de Tanabi, São Paulo, Brasil (2016) 
sulbactam ou ácido clavulânico (18). Essa última associação foi identificada neste estudo. O terceiro, ciprofloxacino, é uma fluorquinolona bactericida por meio da inibição das enzimas topoisomerases bacterianas (tipos II e IV) $(1,2)$. O quarto, azitromicina, é um macrolídeo inibidor da síntese de proteínas bacterianas, utilizado no tratamento das infecções bacterianas do trato respiratório, e também nas infecções da pele e dos tecidos moles $(19,20)$. Todos os antimicrobianos citados apresentam amplo espectro de ação principalmente contra bactérias aeróbias (1,2,17-20).

Os prescritores mais frequentes foram médicos generalistas, seguidos por dentistas, cardiologistas e urologistas. Por outro lado, um estudo realizado em Manaus, AM apontou Ginecologia, Oftalmologia e Medicina do Trabalho, como as especialidades médicas mais frequentes nas prescrições de antibacterianos (16). Em Jataí, GO, os pesquisadores relataram prescrições por dentistas, e não houve especificação das especialidades médicas (10).

A legislação brasileira vigente torna obrigatório, no âmbito do SUS, a prescrição utilizando exclusivamente a DCB, ou seja, a nomenclatura genérica (21). Neste estudo, pouco mais da metade das prescrições foi advinda do sistema privado de saúde; dado semelhante ao encontrado em João Pessoa, PB (11). Os prescritores utilizaram a nomenclatura genérica em quase metade dos antibacterianos prescritos; no entanto, um terço dos antibacterianos prescritos pelo nome comercial foi destinado ao SUS. Em João Pessoa, PB e Manaus, AM, menos da metade dos antibacterianos foram prescritos utilizando a nomenclatura genérica $(11,16)$. Por outro lado, em Colider, MT, metade das prescrições continha a nomenclatura genérica (13).

Foi observado um maior consumo de antibacterianos nos meses de inverno, junho a setembro. Esta sazonalidade pode estar superestimada pelo fato de que, nessas épocas do ano, as sintomatologias comuns das morbidades alérgicas e virais podem acarretar prescrição precipitada de antibacterianos (22).

Uma revisão sistemática, publicada em 2015, apontou a falta de conhecimento da população sobre o uso de antibacterianos, principalmente, o desconhecimento sobre a ação antibacteriana e sobre a inutilidade contra vírus. Além disso, essa revisão também destacou a falta de conhecimento sobre a resistência bacteriana e mostrou a interrupção abrupta após melhora dos sintomas (23).

Embora não tenha sido avaliada a indicação para o uso de antibacterianos neste estudo, é fato que a utilização desses medicamentos de forma abusiva e desnecessária, implica diretamente no desenvolvimento da resistência bacteriana, acarretando riscos à população $(3,4,23)$.

Alguns métodos podem ser utilizados para avaliar e controlar o avanço da resistência bacteriana como: 1 - a caracterização do perfil de prescrição dos antibacterianos, principal foco deste estudo; 2 - a elaboração de protocolos terapêuticos para processos infecciosos diversos; 3 - o treinamento e a formação dos prescritores; 4 - a conscientização da população sobre os riscos do uso abusivo de antibacterianos; 5 - a correta higienização das mãos; 6 - o monitoramento de pacientes infectados por bactérias multirresistentes; 7 - a atuação efetiva do farmacêutico clínico no controle da prescrição e dispensação de antibacterianos $(3,4,24)$.

O propósito do papel do farmacêutico nessa área é realizar o cuidado farmacêutico visando a prevenção, identificação e a resolução de problemas relacionados ao uso de antibacterianos, buscando melhores resultados terapêuticos e prevenindo a utilização irracional. Especificamente, o farmacêutico é capaz de colaborar para o uso racional dos antibacterianos pelo seguimento farmacoterapêutico e das orientações durante o ato da dispensação, identificando a necessidade, efetividade e segurança das terapias antimicrobianas prescritas $(7,8)$.

Ademais, a integração entre prescritores e dispensadores é fundamental, pois permite uma combinação de conhecimentos especializados e complementares. Uma revisão sistemática, que avaliou as intervenções para facilitar a tomada de decisão médica compartilhada para abordar o uso de antibacterianos em infecções agudas do sistema respiratório na atenção primária, destaca a decisão compartilhada oferecendo oportunidade de redução da prescrição de antibacterianos e melhora no uso racional (24).

\section{CONCLUSÃO}

Beta-lactâmicos, fluorquinolonas e macrolídeos foram os medicamentos mais adquiridos na drogaria. $\mathrm{O}$ consumo foi maior no sexo feminino e nos meses de inverno. Esta pesquisa contribui na avaliação do uso de medicamentos antibacterianos no município de Tanabi. A atuação efetiva do farmacêutico no controle do uso de antibacterianos de acordo com a legislação vigente é importante para prover a população com orientações adequadas sobre o uso racional desses agentes. 


\section{REFERÊNCIAS}

1. Brunton L, Chabner BA, Knollmann B. Goodman \& Gilman: As Bases Farmacológicas da Terapêutica. 12. ed. São Paulo: McGraw-Hill, p. 1365-1548, 2012.

2. Almeida FB, Cabral SAAO, Alencar MCB, Figueiredo CHA, Silveira DC, Farias WKA. Atenção farmacêutica em análises da dispensação de antimicrobiano em farmácia. REBES. 2015;5(4):23-29.

3. Faria TV, Pessalacia JDR, Silva ES. Fatores de risco no uso de antimicrobianos em uma instituição hospitalar: reflexões bioéticas. Acta Bioeth. 2016;22(2):321-329. DOI: $10.4067 / \mathrm{S} 1726-569 X 2016000200019$.

4. Loureiro RJ, Fátima Roque F, Rodrigues AT, Herdeiro MT, Ramalheira E. O uso de antibióticos e as resistências bacterianas: breves notas sobre a sua evolução. Rev Port Saude Publica. 2016;34(1):77-84. DOI: 10.1016/j. rpsp.2015.11.003.

5. BRASIL. Agência Nacional de Vigilância Sanitária. Resolução $n^{\circ} 44$, de 26 de outubro de 2010. Dispõe sobre o controle de medicamentos à base de substâncias classificadas como antimicrobianos, de uso sob prescrição médica, isoladas ou em associação e dá outras providências. Diário Oficial da União, ${ }^{\circ} 87,09$ de maio de 2011. Seção 1. p. 39-41.

6. BRASIL. Agência Nacional de Vigilância Sanitária. Resolução $n^{\circ} 20$, de 5 de maio de 2011. Dispõe sobre o controle de medicamentos à base de substâncias classificadas como antimicrobianos, de uso sob prescrição, isoladas ou em associação. Diário Oficial da União, no 207, 28 de outubro de 2010. Seção 1. p. 76.

7. Guedes R, Guedes R, Silva Guedes H. O papel educativo do farmacêutico frente ao desafio da implantação da RDC-20/2011: da automedicação ao consumo consciente de antimicrobianos. Rev Gestao \& Saude. 2014;5(2):436458. DOI: 10.18673/gs.v5i2.22776.

8. Franco JMPL, Mendes RC, Cabral FRF, Menezes CDA. $\mathrm{O}$ papel do farmacêutico frente à resistência bacteriana ocasionada pelo uso irracional de antimicrobianos. Rev Cientifica Semana Academica. 2015;1(72):1-17.

9. IBGE. Instituto Brasileiro de Geografia e Estatística. Tanabi, São Paulo, estimativa da população 2016; 2016 [1 tela]. [citado em 2017 Julho 10]. Disponível em: http:// www.cidades.ibge.gov.br/xtras/temas.php?lang=\&codmun $=355340 \&$ idtema $=130 \&$ search $=$ sao-paulo $\% 7$ Ctanabi\% $7 \mathrm{C}$ -

10. Braoios A, Pereira ACS, Bizerra AA, Policarpo OF, Soares NC, Barbosa AS. Uso de antimicrobianos pela população da cidade de Jataí (GO), Brasil. Cienc Saude Coletiva. 2013;18(10):3055-3060. DOI: 10.1590/S141381232013001000030 .
11. Paula CGD. Análise de prescrições de medicamentos antimicrobianos dispensados em uma farmácia comunitária do município de João Pessoa/PB. Rev Especialize IPOG. 2014;1(9):1-14.

12. Deuschle VCKN, Deuschle RAN, Marques UCF. Avaliação da prevalência da dispensação de antimicrobianos na farmácia pública do município de Cruz Alta - RS. Rev Eletron Farmacia. 2015;12(2):1-15. DOI: 10.5216/ref. v12i2.21155.

13. Guenze Junior A. Análise das prescrições de antimicrobianos dispensados em uma drogaria da cidade de Colider - MT. FACIDER Rev Científica. 2015;8(1):1-15.

14. Carvalho CI. Infecção do trato urinário associado às gestantes e o papel do farmacêutico no tratamento farmacoterapêutico. FACIDER Rev Cientifica. 2015;8(7):1-18.

15. Brito AF, Cruz MXS, Santos NG. Perfil da dispensação de antibióticos em drogarias na cidade de Uruana - GO. REFACER. 2016;5(2):1-14.

16. Nascimento PS, Magalhães IRS. Análise da prescrição de antimicrobianos dispensados em uma rede de drogarias da região Norte do Brasil. Rev Bras de Farm. 2013;94(3):211-218.

17. Serra CHR, Chang KH, Dezani TM, Porta V, Storpirtis S. Dissolution efficiency and bioequivalence study using urine data from healthy volunteers: a comparison between two tablet formulations of cephalexin. Braz J Pharm Sci. 2015;51(2):383-392. DOI: 10.1590/S198482502015000200016 .

18. Hancu G, Neacşu A, Papp LA, Ciurba A. Simultaneous determination of amoxicillin and clavulanic acid in pharmaceutical preparations by capillary zone electrophoresis. Braz J Pharm Sci. 2016;52(2):281-286. DOI: 10.1590/S1984-82502016000200006

19. Machado-Alba JE, Martínez-Pulgarín DF, Gómez-Suta D. Prevalencia de potenciales interacciones farmacológicas de Azitromicina en Colombia, 2012-2013. Rev Salud Publica. 2015;17(3):463-469. DOI: 10.15446/rsap. v17n3.44142.

20. Adeli E. Preparation and evaluation of azithromycin binary solid dispersions using various polyethylene glycols for the improvement of the drug solubility and dissolution rate. Braz J Pharm Sci. 2016;52(1):1-13. DOI: 10.1590/S1984-82502016000100002.

21. BRASIL. Agência Nacional de Vigilância Sanitária. Resolução nº 16, de 02 de março de 2007. Aprova Regulamento Técnico para Medicamentos Genéricos. Diário Oficial da União, n 43, 5 de março de 2007. Seção 1. p. 80. 


\section{Inotama}

22. Coxeter P, Del Mar CB, McGregor L, Beller EM, Hoffmann TC. Interventions to facilitate shared decision making to address antibiotic use for acute respiratory infections in primary care. Cochrane Database Syst Rev. 2015;(11):CD010907. DOI: 10.1002/14651858. CD010907.pub2.

23. Gualano MR, Gili R, Scaioli L, Bert F, SILIQUINI R. Conhecimento e atitudes da população em geral sobre antibióticos: uma revisão sistemática e meta-análise. Pharmacoepidemiol Drug Saf. 2015;24(1):2-10. DOI: 10.1002/pds.3716.
24. Obreli Neto PR, Vieira JC, Cuman RKN. Impacto da atenção farmacêutica no uso racional de antimicrobianos em uma unidade básica de saúde no interior do Estado de São Paulo. Acta Scientiarum Health Sciences. 2011;33(2):159-164. DOI: 10.4025/actascihealthsci. v33i2.8006 